\title{
ÉPOCA DE SEMEADURA, PRODUÇÃO E QUALIDADE FISIOLÓGICA DE SEMENTES DE MILHETO $^{1}$
}

\author{
ROGÉRIO DEANDRADE COIMBRA², JOÃO NAKAGAWA ${ }^{3}$
}

\begin{abstract}
RESUMO - O milheto (Pennisetum americanum (L.) Leeke) é uma gramínea anual, de clima tropical, utilizado no pastejo, na produção de massa e cobertura de solo no sistema de plantio direto. Para estudar o comportamento do milheto, semeado em diferentes épocas do ano em condições de Botucatu, sob túnel plástico, com a finalidade de produção de sementes, foram realizados dois experimentos. No experimento 1, estudou-se nove épocas de semeadura (abril a dezembro), empregando-se a cultivar BN2 e no experimento 2, três épocas (janeiro a março), empregando-se a cultivar Comum. O delineamento experimental foi o de blocos casualizados, com cinco repetições. Foram avaliados componentes da produção, rendimento, germinação e vigor de sementes (primeira contagem do teste de germinação, condutividade elétrica e emergência de plântulas em solo). A época de semeadura afetou a produção e a qualidade das sementes de milheto. A massa de mil sementes e o número de sementes por panícula contribuíram para os melhores resultados da produção. As épocas de semeadura promissoras para produção de sementes milheto em Botucatu são dezembro e janeiro.
\end{abstract}

Temos para indexação: Pennisetum americanum, rendimento, germinação, vigor.

\section{SOWING TIME, PRODUCTIONAND PHYSIOLOGICAL QUALITY OF PEARL MILLET SEEDS}

\begin{abstract}
Pearl millet (Pennisetum americanum (1.) Leeke) is an annual graminea, of tropical climate, used in animal feeding as forage, in direct feeding, for cut, hay, silage and as grain crop for feed. To study the behavior of the pearl millet, sown at different times of the year underconditions in Botucatu, SP, Brazil, under plastic tunnel, with the purpose of seed production, two experiments were carried out. In experiment 1, nine sowing times (April to December) were studied using the BN2 cultivar and in experiment 2, three times (January to March) using the Comun cultivar. A randomized experimental design was used with five replications. The following were evaluated: yield components, yield, seed germination and vigor (first count of the germination test, electrical conductivity and seedling emergence in soil). The sowing time affected the pearl millet seed yield and quality. The mass of 1000 seeds and the number of seeds per panicle contributed to the best yield results. The promising sowing times for pearl millet seed production in Botucatu are December and January.
\end{abstract}

Index terms: Pennisetum americanum, yield, germination, vigor.

\section{INTRODUÇÃO}

O milheto (Pennisetum glaucum (L.) R. Br., P. americanum (L.) Leeke ou $P$. typhoides (Burm F.) J. Stapf e C. E. Hubb) é uma planta anual, da família das gramíneas, de clima tropical, com ciclo de aproximadamente 130 dias. Possui

\footnotetext{
1 Submetido em 02/03/2005. Aceito para publicação em 23/06/2005;

${ }^{2}$ Aluno do Programa de Pós-Gradução em Agronomia, área de concentração Agricultura pela Faculdade de Ciências Agronômica (FCA) - UNESP Campus Botucatu, bolsista CNPq. Depto. de Produção Vegetal. Campus
}

crescimento ereto e porte alto, podendo atingir quatro ou cinco metros de altura, sendo também conhecido como pasto italiano na região sul do Brasil (Salton e Kichel, 1997). É originário, provavelmente, das savanas africanas, apresentando capacidade de produzir grãos ou sementes em condições extremamente secas e em solos de baixa fertilidade, porém

Botucatu, Caixa Postal 237, CEP: 18603-790, Botucatu - SP. racoimbra@fca.unesp.br;

${ }^{3}$ Professor Titular Aposentado - Voluntário, bolsista CNPq. Depto. de Produção Vegetal - FCA - UNESP - Campus Botucatu, Caixa Postal 237, CEP: 18603-790, Botucatu - SP. secdamv@fca.unesp.br. 
respondendo bem às adubações.

Devido a ampla adaptação e boa produção de massa, aliadas ao crescimento rápido, a espécie tem destaque em áreas de plantio direto no Brasil central, como opção de cobertura de solo, particularmente na região do cerrado (Pereira, 1990), com bons resultados para a soja, cultivada em sucessão (Pereira, 1990; Silva, 1998; Salton, 2001; Lemos et al., 2003). A sua procura tem sido grande nos estados de Mato Grosso, Mato Grosso do Sul, Goiás, Bahia, Minas Gerais, São Paulo e Paraná (Netto et al., 1997); como opção de cultivo de inverno, em regiões de cerrado como Mato Grosso e Mato Grosso do Sul, ocupando áreas de 600.000 e 200.000ha, respectivamente (Salton, 2001).

Apesar de mostrar ampla capacidade de adaptação, um melhor conhecimento das características da planta de milheto é fator importante para a expansão e aproveitamento correto da cultura, pois o seu comportamento pode variar em função das diferentes condições ambientais. A época de semeadura do milheto varia de região para região, podendo em locais tropicais ser semeado continuamente (Alcântara e Bufarah, 1988).

Assim, para verificar as possibilidades de adaptação da cultura em uma região, onde as condições climáticas variam no decorrer do ano, há a necessidade da realização de estudos de época de semeadura. Através desses poderão ser definidas as melhores épocas de cultivo do milheto, onde as necessidades ecofisiológicas da planta sejam preenchidas, visando sua utilização como forrageira ou cobertura vegetal do solo, e/ou para produção de grãos ou sementes.

Sabe-se que, para a eficiente germinação das sementes de milheto, é necessário que a temperatura média do solo seja superior a $20^{\circ} \mathrm{C}$, além de haver umidade suficiente para satisfatória emergência das plântulas (Salton e Kichel, 1997). Nas condições do sistema de plantio direto, a ocorrência de precipitações entre 30 e $40 \mathrm{~mm}$ viabiliza boa formação da lavoura de milheto. Salton e Kichel (1997) recomendam a semeadura do milheto, no oeste do Estado de São Paulo, Triângulo Mineiro, sul de Goiás, sul de Mato Grosso e centronorte de Mato Grosso de Sul, no outono, logo após a colheita da safra de verão, visando o aproveitamento das últimas chuvas e conseqüentemente, o melhor estabelecimento da cultura. No sul de Mato Grosso do Sul e no Paraná, a recomendação é para a primavera.

O milheto é uma espécie classificada como de dias curtos, apesar de existirem populações de dias neutros (Burton, 1972; Burger, 1984), podendo a manipulação do fotoperíodo e da temperatura induzir a antese prematura (Hellmers e Burton,
1972).

O objetivo do presente trabalho foi estudar em condições de Botucatu, sob túnel plástico visando o controle de irrigação, o efeito de diferentes épocas de semeadura nos componentes de produção, no rendimento e na qualidade fisiológica de sementes de milheto.

\section{MATERIAL E MÉTODOS}

O experimento foi conduzido na área do Departamento de Produção Vegetal - Agricultura, da Faculdade de Ciências Agronômicas, Campus de Botucatu, UNESP, localizada no município de Botucatu - SP, definida pelas coordenadas geográficas: $815 \mathrm{~m}$ de altitude, $22^{\circ} 50^{\prime} 59^{\prime \prime}$ de latitude sul e $48^{\circ} 25^{\prime} 54^{\prime}$ 'W de Grw. de longitude. Foi executado em condições de túnel plástico, com as seguintes características: $5,20 \mathrm{~m}$ (largura) x 20,00m (comprimento) x 2,5m (pé-direito), revestidos nas faces e lateralmente com tela (abertura de malha $4 \mathrm{~mm}^{2}$ ), e cobertura plástica com filme de polietileno transparente com $150 \mu$ de espessura, sem controle ambiental, e com função específica de proteção contra ataque de pássaros e de controle de irrigação.

Empregaram-se vasos plásticos de $10 \mathrm{~L}$, com $24 \mathrm{~cm}$ de diâmetro. A terra utilizada foi coletada na camada de $0-20 \mathrm{~cm}$ de Nitossolo Vermelho (Oliveira et al., 1999), realizando-se a correção prévia de sua fertilidade, com $20 \mathrm{~g}$ de superfosfato simples, $2,5 \mathrm{~g}$ de cloreto de potássio e $2,0 \mathrm{~g}$ de sulfato de amônio por 10L de terra, antes de colocá-la nos vasos, baseado nos resultados da análise química do solo, que apresentou $\mathrm{pH}$ de 5,$6 ; 52,9 \mathrm{~g} \cdot \mathrm{kg}^{-1}$ de matéria orgânica; $33,3 \mathrm{mg} \cdot \mathrm{dm}^{-3}$ de fósforo (P); 35,7 $\mathrm{mmol}_{c} \cdot \mathrm{dm}^{-3} \mathrm{de}^{+}+\mathrm{Al}^{3+} ; 4,3 \mathrm{mmol}_{c^{\prime}} \cdot \mathrm{dm}^{-3}$ de potássio

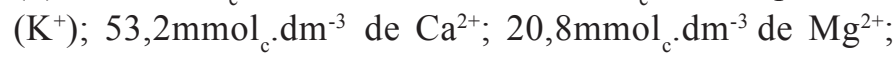
$78,4 \mathrm{mmol}_{\mathrm{c}} \cdot \mathrm{dm}^{-3} \mathrm{de} \mathrm{SB} ; 114,1 \mathrm{mmol}_{\mathrm{c}} \cdot \mathrm{dm}^{-3}$ de CTC e V(\%) de $68,7 \%$.

O delineamento experimental empregado foi de blocos casualizados, com cinco repetições, representadas pelos vasos. Foram realizados dois experimentos, onde as épocas de semeadura constituíram os tratamentos. $\mathrm{O}$ experimento 1 foi constituído por nove épocas de semeadura (abril a dezembro) empregando-se a cultivar BN2, e o experimento 2, por três épocas (janeiro a março), empregando-se a cultivar Comum.

A semeadura foi realizada com número de sementes maior que o necessário, para, após emergência das plântulas, realizarse o desbaste e obter três plantas por vaso. Foram realizadas irrigações diárias, conforme a necessidade, adubações em cobertura com N ( $2 \mathrm{~g}$ de Sulfato de Amônio por vaso) a cada 15 dias, e o controle de pragas e doenças quando necessário. 
Ao final do ciclo da cultura, foram avaliados o número de perfílhos com e sem panícula, o número e a massa de sementes por panícula da haste principal e dos perfílhos e o comprimento da panícula da haste principal e dos perfílhos. Com estes dados foram calculadas as porcentagens de perfílhos úteis, a massa de mil sementes da panícula da haste principal e dos perfílhos e a produção de sementes por planta.

Em laboratório foram feitas as seguintes avaliações: (a) Massa de mil sementes (Brasil, 1992), (b) Teor de água das sementes, pelo método da estufa a $1053^{\circ} \mathrm{C}$ por 24 horas (Brasil, 1992), (c) Germinação, utilizando-se temperaturas alternadas de $20-30^{\circ} \mathrm{C}$ em substrato papel-toalha (RP) com 100 sementes por repetição (Brasil, 1992); as sementes dormentes foram computadas ao final do teste de germinação, sendo consideradas aquelas que permaneceram duras, ou seja, não embeberam durante o teste e (d) Vigor, por meio da primeira contagem do teste de germinação, da condutividade elétrica e da emergência em solo. A primeira contagem da germinação foi realizada em conjunto com o teste de germinação (Brasil, 1992). Os dados de condutividade elétrica foram obtidos pelo método de massa, com duas amostras de 50 sementes por repetição que, após pesadas, foram colocadas em copos plásticos de $200 \mathrm{~mL}$ contendo $75 \mathrm{~mL}$ de água destilada e mantidas por $24 \mathrm{~h}$ em câmara a $25^{\circ} \mathrm{C}$; após esse período foi feita a leitura em condutivímetro e os valores obtidos foram calculados em $\mu \mathrm{S} . \mathrm{cm}^{-1} \cdot \mathrm{g}^{-1}$ (Vieira e Carvalho, 1994). A emergência de plântulas foi determinada em bandejas plásticas de $41 \mathrm{~cm}$ x $26 \mathrm{~cm}$ x $8 \mathrm{~cm}$ com capacidade aproximada de $8,5 \mathrm{~L}$ de terra, onde foram semeadas 100 sementes por repetição; as bandejas foram colocadas sob túnel plástico, com irrigações quando necessário e foram realizadas contagens diárias das plântulas emergidas até que este número se estabilizasse.

Os dados em porcentagem e contagem (em número) que apresentaram valores nulos foram transformados em (x $+0,5)^{1 / 2}$ e os de contagem sem valor nulo, transformados em $(\mathrm{x})^{1 / 2}$, para a seguir, serem submetidos à análise estatística (Gomes, 2000; Barbin, 2003). Os demais dados foram analisados sem transformação. As médias foram comparadas pelo teste Tukey a 5\% de significância. As médias apresentadas nas tabelas são dos dados originais.

\section{RESULTADOS E DISCUSSÃO}

Experimento 1: Observou-se pelo número de perfílhos com panícula e pela porcentagem de perfílhos úteis, que a emissão do perfilho não implica necessariamente na formação da panícula (Tabela 1). Segundo Raufurd e Bidinger (1988) esses sugerem que em milheto a seleção visando ao aumento do número de panículas não deve resultar em aumento significativo no potencial produtivo, pela relação inversa com o tamanho da panícula, e que o aumento na produção deve vir através do aumento do número de grãos.

A porcentagem de perfílhos úteis foi maior para as épocas de semeadura de maio, abril e junho respectivamente (Tabela 1). Estudos realizados por Hellmers e Burton (1972) verificaram que a manipulação do fotoperíodo e da temperatura pode induzir mudanças na ocorrência da antese e no número de panículas formadas por planta. No presente experimento os maiores números de perfílhos com panícula

TABELA 1. Valores médios de número de perfílhos com panícula (NPP), porcentagem de perfílhos úteis (PU), número de sementes por panícula da haste principal (NSHP), número de sementes por panícula dos perfílhos (NSP), comprimento da panícula da haste principal (CPHP) e comprimento da panícula da haste dos perfílhos (CPP) por planta de milheto em função da época de semeadura. Botucatu, 2000. Experimento 1.

\begin{tabular}{ccclcrcc}
\hline Trat. & $\begin{array}{c}\text { CICLO } \\
(\mathbf{d i a s})\end{array}$ & $\begin{array}{l}\text { NPP } \\
\left(\mathbf{N}^{\circ}\right)\end{array}$ & $\begin{array}{l}\text { PU } \\
(\mathbf{\%})\end{array}$ & $\begin{array}{c}\text { NSHP } \\
\left(\mathbf{N}^{\circ}\right)\end{array}$ & $\begin{array}{c}\mathbf{N S P} \\
\left(\mathbf{N}^{\circ}\right)\end{array}$ & $\begin{array}{c}\mathbf{C P H P} \\
(\mathbf{c m})\end{array}$ & $\begin{array}{c}\mathbf{C P P} \\
(\mathbf{c m})\end{array}$ \\
\hline $\mathbf{A b r}$ & 130 & $2,13 \mathrm{AB}$ & $86,50 \mathrm{AB}$ & $410 \mathrm{D}$ & $1048 \mathrm{~A}$ & $18,99 \mathrm{~B}$ & $14,46 \mathrm{~A}$ \\
Mai & 132 & $2,27 \mathrm{AB}$ & $90,31 \mathrm{~A}$ & $473 \mathrm{CD}$ & $389 \mathrm{~A}$ & $18,47 \mathrm{~B}$ & $18,08 \mathrm{~A}$ \\
Jun & 140 & $3,37 \mathrm{~A}$ & $74,18 \mathrm{ABC}$ & $646 \mathrm{CD}$ & $1121 \mathrm{~A}$ & $26,03 \mathrm{~A}$ & $20,15 \mathrm{~A}$ \\
Jul & 137 & $2,07 \mathrm{AB}$ & $58,15 \mathrm{ABC}$ & $881 \mathrm{BCD}$ & $1142 \mathrm{~A}$ & $24,17 \mathrm{AB}$ & $19,68 \mathrm{~A}$ \\
Ago & 118 & $0,90 \mathrm{BC}$ & $34,32 \mathrm{BCD}$ & $1121 \mathrm{ABC}$ & $763 \mathrm{~A}$ & $23,73 \mathrm{AB}$ & $17,40 \mathrm{~A}$ \\
Set & 111 & $0,53 \mathrm{C}$ & $31,98 \mathrm{CD}$ & $1926 \mathrm{~A}$ & $964 \mathrm{~A}$ & $26,37 \mathrm{~A}$ & $20,29 \mathrm{~A}$ \\
Out & 124 & $0,80 \mathrm{BC}$ & $33,51 \mathrm{BCD}$ & $1503 \mathrm{AB}$ & $1019 \mathrm{~A}$ & $25,93 \mathrm{~A}$ & $18,72 \mathrm{~A}$ \\
Nov & 116 & $0,33 \mathrm{C}$ & $12,43 \mathrm{D}$ & $1429 \mathrm{AB}$ & $524 \mathrm{~A}$ & $27,14 \mathrm{~A}$ & $17,10 \mathrm{~A}$ \\
Dez & 112 & $0,33 \mathrm{C}$ & $18,66 \mathrm{D}$ & $1740 \mathrm{~A}$ & $348 \mathrm{~A}$ & $27,28 \mathrm{~A}$ & $19,25 \mathrm{~A}$ \\
C.V. & - & 20,15 & 28,34 & 17,89 & 36,11 & 12,24 & 16,06 \\
\hline
\end{tabular}

Médias na mesma coluna seguidas da mesma letra não diferem entre si pelo teste de Tukey ao nível de 5\%. 
e percentuais de perfílhos úteis foram observados nas semeaduras em dias curtos de outono e inverno do que em dias longos de primavera.

O número de sementes da haste principal acompanhou o comprimento de suas panículas para a maioria das épocas de semeadura; já para os perfílhos esta relação não foi observada (Tabela 1). Isto indica que para as panículas dos perfílhos, as épocas que proporcionaram condições favoráveis para o desenvolvimento da raque nem sempre foram propícias para a formação de sementes, resultando em panículas com menos sementes.

O comprimento da panícula da haste principal superou em todas as épocas o comprimento das panículas dos perfílhos, embora para estes as variações desses comprimentos no decorrer das nove épocas tenham sido semelhantes. As épocas com maior comprimento de panícula da haste principal, que também apresentaram maiores valores numéricos de comprimento das panículas dos perfílhos foram, junho, julho, setembro e dezembro, porém essas não foram as que as que apresentaram maior número de sementes (Tabela 1).

A massa de mil sementes da panícula da haste principal sofreu efeito das épocas de semeadura; isso não foi observado para as sementes da panícula dos perfílhos, das quais exceto abril, todas as épocas apresentaram menor massa em relação à haste principal (Tabela 2). Para as panículas da haste principal, a maioria das épocas favoráveis para a formação do maior número de sementes (Tabela 1), foram também favoráveis ao acúmulo de massa nas sementes (Tabela 2).
A produção de sementes (g.planta-1) foi elevada para as épocas de semeadura de julho, junho e dezembro, nesta seqüência (Tabela 2). Para a semeadura de dezembro houve maior contribuição da panícula da haste principal na produção, enquanto para junho e julho a haste principal e os perfílhos apresentaram contribuições semelhantes na produção de sementes.

Tanto para a produção de sementes da haste principal como dos perfílhos, a maior contribuição dentre os componentes foi o número de sementes, seguido da massa da semente e comprimento das panículas. Geraldo et al. (2000), em trabalho entre fevereiro e maio, observaram para as cultivares de milheto BN2 e IAPAR, que a produção de grãos foi positivamente correlacionada com a massa de mil sementes e com o comprimento da panícula, e negativamente correlacionada com o número de panículas.

Outro aspecto a ressaltar é que as maiores produções foram obtidas nas épocas que proporcionaram os maiores ciclos culturais, 137 dias em julho e 140 dias em junho, e em um dos menores, 112 dias em dezembro (Tabela 1).

$\mathrm{O}$ teor de água das sementes, por ocasião das avaliações de qualidade, apresentou variações de no máximo 1,2 pontos percentuais entre as épocas (Tabela 3), o que leva a inferir que este não deve ter afetado os resultados das avaliações de qualidade.

A germinação foi máxima na semeadura de dezembro (96\%), e mínima em novembro (88\%), mantendo-se entre $90 \%$ e $92 \%$ nas demais épocas (Tabela 3). A menor porcentagem de sementes dormentes contribuiu para maior

TABELA 2. Valores médios de massa de 1000 sementes da panícula da haste principal (M1000HP), massa de 1000 sementes por panícula dos perfílhos (M1000P), produção total (PRODT), produção de sementes da haste principal (PRODHP) e produção de sementes dos perfílhos (PRODP) por planta de milheto em função da época de semeadura. Botucatu, 2000. Experimento 1.

\begin{tabular}{cccccc}
\hline Trat. & $\begin{array}{c}\text { M1000HP } \\
(\mathrm{g})\end{array}$ & $\begin{array}{c}\text { M1000P } \\
(\mathrm{g})\end{array}$ & $\begin{array}{c}\text { PRODT } \\
(\mathrm{g})\end{array}$ & $\begin{array}{c}\text { PRODHP } \\
(\mathrm{g})\end{array}$ & $\begin{array}{c}\text { PRODP } \\
(\mathrm{g})\end{array}$ \\
\hline Abr & $4,70 \mathrm{C}$ & $4,84 \mathrm{~A}$ & $11,77 \mathrm{AB}$ & $5,39 \mathrm{BC}$ & $6,38 \mathrm{AB}$ \\
Mai & $4,88 \mathrm{BC}$ & $3,76 \mathrm{~A}$ & $5,18 \mathrm{C}$ & $2,69 \mathrm{C}$ & $2,49 \mathrm{BC}$ \\
Jun & $6,21 \mathrm{ABC}$ & $4,40 \mathrm{~A}$ & $15,45 \mathrm{AB}$ & $7,79 \mathrm{AB}$ & $7,68 \mathrm{~A}$ \\
Jul & $6,29 \mathrm{ABC}$ & $5,30 \mathrm{~A}$ & $17,45 \mathrm{~A}$ & $9,40 \mathrm{AB}$ & $8,05 \mathrm{~A}$ \\
Ago & $6,98 \mathrm{~A}$ & $4,54 \mathrm{~A}$ & $11,60 \mathrm{AB}$ & $9,18 \mathrm{AB}$ & $2,42 \mathrm{BC}$ \\
Set & $5,12 \mathrm{ABC}$ & $3,66 \mathrm{~A}$ & $11,61 \mathrm{AB}$ & $11,12 \mathrm{~A}$ & $0,49 \mathrm{C}$ \\
Out & $6,03 \mathrm{ABC}$ & $4,59 \mathrm{~A}$ & $11,43 \mathrm{~B}$ & $8,85 \mathrm{AB}$ & $2,58 \mathrm{BC}$ \\
Nov & $6,17 \mathrm{ABC}$ & $3,53 \mathrm{~A}$ & $10,70 \mathrm{BC}$ & $8,74 \mathrm{AB}$ & $1,96 \mathrm{C}$ \\
Dez & $6,84 \mathrm{AB}$ & $5,69 \mathrm{~A}$ & $15,08 \mathrm{AB}$ & $11,70 \mathrm{~A}$ & $3,38 \mathrm{BC}$ \\
\hline C.V. & 15,95 & 30,18 & 23,15 & 25,57 & 49,25 \\
\hline
\end{tabular}

Médias na mesma coluna seguidas da mesma letra não diferem entre si pelo teste de Tukey ao nível de 5\%. 
germinação de dezembro; para as demais épocas de semeadura, somente a presença das sementes dormentes não explica as variações de germinação.

Pelos testes de vigor empregados, a emergência de plântulas em solo, embora sem diferenças estatísticas, apresentou comportamento semelhante ao da germinação; já para primeira contagem e condutividade elétrica, a classificação dos tratamentos não acompanhou as variações da germinação (Tabela 3).

Experimento 2: À semelhança do experimento 1, observou-se pelo número de perfílhos com panícula e pela porcentagem de perfílhos úteis, que a emissão do perfilho não implica necessariamente na formação da panícula (Tabela 4). A porcentagem de perfílhos úteis foi maior para as épocas de semeadura de fevereiro e março (Tabela 4), provavelmente influenciada pelas alterações de temperatura e diminuição do fotoperíodo no decorrer do seu ciclo (Tabela 4), confirmando assim a hipótese de que alterações do fotoperíodo e da temperatura podem induzir mudanças na ocorrência da antese e no número de panículas por planta (Hellmers e Burton, 1972).
O número de sementes da haste principal e dos perfílhos, não variou estatisticamente entre as épocas de semeadura; o mesmo foi observado para o comprimento da panícula da haste principal e dos perfílhos (Tabela 4). Isto indica que a época de semeadura não influenciou o desenvolvimento da raque e nem o número de sementes produzidas por essas.

A massa de mil sementes da panícula da haste principal e dos perfílhos também não sofreu efeito das épocas de semeadura (Tabela 5). Entretanto, a massa de mil sementes da haste principal foi superior numericamente à dos perfílhos em todas as épocas, à semelhança do observado no experimento 1 (Tabela 2), apesar de serem cultivares diferentes. Isso indica que as sementes produzidas pela haste principal, mesmo que em menor número (Tabela 4), por estarem melhor formadas (maior massa), contribuíram para a maior produção (Tabela 5) e melhor qualidade das sementes (Tabela 6).

A produção total de sementes (g.planta ${ }^{-1}$ ), não diferiu estatisticamente entre as épocas (Tabela 5), embora tenha apresentado tendência de diminuição da produção com o atraso

TABELA 3. Valores médios de teor de água (TA), germinação (GE), sementes dormentes (SD), vigor (primeira contagem do teste de germinação (PC), condutividade elétrica (CE) e emergência de plântulas em solo(EP)) de sementes de milheto em função da época de semeadura. Botucatu, 2000. Experimento 1.

\begin{tabular}{ccccccc}
\hline Trat. & $\begin{array}{c}\text { TA } \\
(\%)\end{array}$ & $\begin{array}{c}\text { GE } \\
(\%)\end{array}$ & $\begin{array}{c}\text { SD } \\
(\%)\end{array}$ & $\begin{array}{c}\text { PC } \\
(\%)\end{array}$ & $\begin{array}{c}\text { CE } \\
\left(\mu S \cdot \mathrm{cm}^{-1} \cdot \mathrm{g}^{-1}\right)\end{array}$ & $\begin{array}{c}\mathrm{EP} \\
(\%)\end{array}$ \\
\hline Abr & $9,3 \mathrm{~B}$ & $92 \mathrm{AB}$ & $4,7 \mathrm{ABC}$ & $86 \mathrm{~A}$ & $103,08 \mathrm{ABC}$ & $91 \mathrm{~A}$ \\
Mai & $9,3 \mathrm{~B}$ & $91 \mathrm{AB}$ & $5,0 \mathrm{ABC}$ & $83 \mathrm{~A}$ & $114,18 \mathrm{~A}$ & $85 \mathrm{~A}$ \\
Jun & $9,1 \mathrm{~B}$ & $92 \mathrm{AB}$ & $4,4 \mathrm{BC}$ & $85 \mathrm{~A}$ & $91,17 \mathrm{ABC}$ & $92 \mathrm{~A}$ \\
Jul & $9,1 \mathrm{~B}$ & $92 \mathrm{AB}$ & $5,3 \mathrm{ABC}$ & $82 \mathrm{~A}$ & $73,03 \mathrm{BCD}$ & $95 \mathrm{~A}$ \\
Ago & $9,0 \mathrm{~B}$ & $90 \mathrm{AB}$ & $7,00 \mathrm{AB}$ & $78 \mathrm{AB}$ & $51,50 \mathrm{D}$ & $95 \mathrm{~A}$ \\
Set & $10,1 \mathrm{~A}$ & $91 \mathrm{AB}$ & $11,3 \mathrm{~A}$ & $84 \mathrm{~A}$ & $68,14 \mathrm{CD}$ & $87 \mathrm{~A}$ \\
Out & $9,8 \mathrm{~A}$ & $90 \mathrm{AB}$ & $4,6 \mathrm{BC}$ & $60 \mathrm{~B}$ & $103,98 \mathrm{AB}$ & $83 \mathrm{~A}$ \\
Nov & $10,2 \mathrm{~A}$ & $88 \mathrm{~B}$ & $5,0 \mathrm{ABC}$ & $83 \mathrm{~A}$ & $91,09 \mathrm{ABC}$ & $84 \mathrm{~A}$ \\
Dez & $10,2 \mathrm{~A}$ & $96 \mathrm{~A}$ & $2,0 \mathrm{C}$ & $94 \mathrm{~A}$ & $78,89 \mathrm{ABCD}$ & $96 \mathrm{~A}$ \\
\hline C.V. & 1,80 & 3,48 & 24,84 & 11,18 & 19,75 & 8,25 \\
\hline
\end{tabular}

Médias na mesma coluna seguidas da mesma letra não diferem entre si pelo teste de Tukey ao nível de 5\%.

TABELA4. Valores médios de número de perfílhos com panícula (NPP), porcentagem de perfílhos úteis (PU), número de sementes por panícula da haste principal (NSHP), número de sementes por panícula dos perfílhos (NSP), comprimento da panícula da haste principal (CPHP) e comprimento da panícula da haste dos perfílhos (CPP) por planta de milheto em função da época de semeadura. Botucatu, 2000. Experimento 2.

\begin{tabular}{cccccccc}
\hline Trat. & $\begin{array}{c}\text { CICLO } \\
(\text { dias })\end{array}$ & $\begin{array}{c}\text { NPP } \\
\left(\mathrm{N}^{\circ}\right)\end{array}$ & $\begin{array}{c}\text { PU } \\
(\%)\end{array}$ & $\begin{array}{c}\text { NSHP } \\
\left(\mathrm{N}^{\circ}\right)\end{array}$ & $\begin{array}{c}\text { NSP } \\
\left(\mathrm{N}^{\circ}\right)\end{array}$ & $\begin{array}{c}\text { CPHP } \\
(\mathrm{cm})\end{array}$ & $\begin{array}{c}\text { CPP } \\
(\mathrm{cm})\end{array}$ \\
\hline Jan & 107 & $1,60 \mathrm{~B}$ & $58,40 \mathrm{~B}$ & $1088 \mathrm{~A}$ & $1176 \mathrm{~A}$ & $15,10 \mathrm{~A}$ & $11,15 \mathrm{~A}$ \\
$\mathrm{Fev}$ & 104 & $1,93 \mathrm{AB}$ & $86,40 \mathrm{~A}$ & $756 \mathrm{~A}$ & $1276 \mathrm{~A}$ & $15,10 \mathrm{~A}$ & $12,47 \mathrm{~A}$ \\
Mar & 122 & $3,00 \mathrm{~A}$ & $93,44 \mathrm{~A}$ & $684 \mathrm{~A}$ & $668 \mathrm{~A}$ & $14,41 \mathrm{~A}$ & $11,42 \mathrm{~A}$ \\
\hline C.V. & - & 11,93 & 10,81 & 18,62 & 18,55 & 11,00 & 12,19 \\
\hline
\end{tabular}

Médias na mesma coluna seguidas da mesma letra não diferem entre si pelo teste de Tukey ao nível de 5\%. 
TABELA 5. Valores médios de massa de 1000 sementes da panícula da haste principal (M1000HP), massa de 1000 sementes por panícula dos perfílhos (M1000P), produção total (PRODT), produção de sementes da haste principal (PRODHP) e produção de sementes dos perfílhos (PRODP) por planta de milheto em função da época de semeadura. Botucatu, 2000. Experimento 2.

\begin{tabular}{cccccc}
\hline Trat. & $\begin{array}{c}\text { M1000HP } \\
(\mathrm{g})\end{array}$ & $\begin{array}{c}\text { M1000P } \\
(\mathrm{g})\end{array}$ & $\begin{array}{c}\text { PRODT } \\
(\mathrm{g})\end{array}$ & $\begin{array}{c}\text { PRODHP } \\
(\mathrm{g})\end{array}$ & $\begin{array}{c}\text { PRODP } \\
(\mathrm{g})\end{array}$ \\
\hline Jan & $6,36 \mathrm{~A}$ & $4,31 \mathrm{~A}$ & $15,36 \mathrm{~A}$ & $9,30 \mathrm{~A}$ & $6,06 \mathrm{~A}$ \\
Fev & $5,79 \mathrm{~A}$ & $3,69 \mathrm{~A}$ & $13,46 \mathrm{~A}$ & $4,71 \mathrm{AB}$ & $8,75 \mathrm{~A}$ \\
Mar & $4,95 \mathrm{~A}$ & $3,56 \mathrm{~A}$ & $9,61 \mathrm{~A}$ & $3,86 \mathrm{~B}$ & $5,75 \mathrm{~A}$ \\
\hline C.V. & 18,17 & 33,10 & 29,50 & 50,36 & 33,95 \\
\hline
\end{tabular}

Médias na mesma coluna seguidas da mesma letra não diferem entre si pelo teste de Tukey ao nível de 5\%.

TABELA 6. Valores médios de teor de água das sementes (TA), germinação (GE), sementes dormentes (SD), vigor (primeira contagem do teste de germinação (PC), condutividade elétrica (CE) e emergência de plântulas em solo (EP)) de sementes de milheto em função da época de semeadura. Botucatu, 2000. Experimento 2.

\begin{tabular}{|c|c|c|c|c|c|c|}
\hline Trat. & $\begin{array}{l}\text { TA } \\
(\%)\end{array}$ & $\begin{array}{l}\mathrm{GE} \\
(\%)\end{array}$ & $\begin{array}{l}\mathrm{SD} \\
(\%)\end{array}$ & $\begin{array}{l}\mathrm{PC} \\
(\%)\end{array}$ & $\begin{array}{c}\mathrm{CE} \\
\left(\mathrm{S} \cdot \mathrm{cm}^{-1} \cdot \mathrm{g}^{-1}\right)\end{array}$ & $\begin{array}{l}\mathrm{EP} \\
(\%)\end{array}$ \\
\hline Jan & $9,2 \mathrm{~A}$ & $97 \mathrm{~A}$ & $0,8 \mathrm{~A}$ & $95 \mathrm{~A}$ & $78,38 \mathrm{~B}$ & $95 \mathrm{~A}$ \\
\hline Fev & $9,2 \mathrm{~A}$ & $95 \mathrm{~A}$ & $2,4 \mathrm{~A}$ & $91 \mathrm{~A}$ & $97,48 \mathrm{AB}$ & $90 \mathrm{~A}$ \\
\hline Mar & $9,1 \mathrm{~A}$ & $95 \mathrm{~A}$ & $3,2 \mathrm{~A}$ & $90 \mathrm{~A}$ & $115,69 \mathrm{~A}$ & $89 \mathrm{~A}$ \\
\hline C.V. & 1,41 & 3,55 & 33,65 & 6,49 & 20,83 & 7,83 \\
\hline
\end{tabular}

Médias na mesma coluna seguidas da mesma letra não diferem entre si pelo teste de Tukey ao nível de $5 \%$.

da semeadura. Já a produção de sementes da haste principal apresentou diferenças significativas, havendo queda na produção com o atraso da semeadura; o mesmo não foi observado na produção de sementes dos perfílhos (Tabela 5). Essa redução na produção está relacionada à diminuição da temperatura média, ou seja, o atraso da semeadura aumentou o ciclo de desenvolvimento da planta (Tabela 4) estendendo-o pelos meses de outono e inverno, sendo que as temperaturas médias registradas de janeiro a julho foram respectivamente 22,$6 ; 21,4 ; 21,6 ; 21,3 ; 18,1 ; 18,6$ e $15,3^{\circ} \mathrm{C}$.

Geraldo et al. (2000) relatam que elevados rendimentos de grãos podem ser atribuídos à boa disponibilidade hídrica no cultivo, associada a temperaturas adequadas (média de $25,3^{\circ} \mathrm{C}$ ), dentro da faixa ótima de 25 a $27^{\circ} \mathrm{C}$ para máxima taxa de crescimento do milheto.

O teor de água das sementes, por ocasião das avaliações de qualidade, não apresentou variação entre as épocas (Tabela 6), o que leva a inferir que este fator também não deve ter afetado os resultados das avaliações de qualidade neste experimento.

Os testes germinação, sementes dormentes, primeira contagem e emergência de plântulas não apresentaram diferenças estatísticas entre as épocas (Tabela 6), apesar de, no geral, manterem tendência de diminuição. Já o teste de condutividade elétrica distinguiu estatisticamente as épocas, sendo janeiro a de melhor qualidade, fevereiro de qualidade intermediária e março de qualidade inferior (Tabela 6). Essas variações entre épocas podem ser atribuídas às diferenças de massa (Tabela 5) das sementes produzidas pelos perfílhos e pela haste principal, ou seja, sementes menores apresentam uma maior área de contato para uma mesma massa de sementes no teste de condutividade elétrica; sendo assim, há uma alta relação entre a superfície por unidade de massa nas sementes pequenas (Tao, 1978; Hepburn et al., 1984; Siddique e Goodwin, 1985), resultando em maiores perdas de lixiviados, menor vigor e qualidade das sementes (Tabela 6).

\section{CONCLUSÕES}

A época de semeadura afeta a produção e a qualidade das sementes de milheto.

A massa de mil sementes e o número de sementes por panícula contribuem para os melhores resultados da produção.

As épocas de semeadura promissoras para produção de sementes de milheto em Botucatu são dezembro e janeiro. 


\section{AGRADECIMENTOS}

A FAPESP, pela bolsa de iniciação científica concedida ao primeiro autor, para o desenvolvimento deste trabalho científico, durante a graduação.

\section{REFERÊNCIAS}

ALCÂNTARA, P.B.; BUFARAH, G. Plantas forrageiras: gramíneas e leguminosas, 4 ed. rev.e ampl. São Paulo: Nobel, 1988. 162 p.

BARBIN, D. Planejamento e análise de experimentos agronômicos. Arapongas: Midas, 2003. 208p.

BRASIL, Ministério da Agricultura e Reforma Agrária. Regras para análise de sementes. Brasília: SNDA/DNDV/CLV, 1992.365p.

BURGER, A.W. Crop classification. In: TESAR, M.B. (Ed.) Physiological bases of crop growth and development. Madison: American Society of Agronomy, 1984. p.01-12.

BURTON, G.W. Registration of Tiflate pearl millet. Crop Science, Madison, v.12, n.1, p.128, 1972.

CRAUFURD, P.Q.; BIDINGER, F.R. Effect of the duration of the vegetative phase on shoot growth, development and yield in pearl millet (Pennisetum americanum (L.) Leeke). Journal of Experimental Botany, Oxford, v.39, p.124-139, 1988.

GERALDO, J.; ROSSIELLO, R.O.P.; ARAÚJO, A.P.; PIMENTEL, C. Diferenças em crescimento e produção de grãos entre quatro cultivares de milheto pérola. Pesquisa Agropecuária Brasileira, Brasília, v.35, n.7, p.1367-1376, 2000.

GOMES, F.P. Curso de estatística experimental. $14^{\circ}$ ed. Piracicaba: ESALQ, 2000. 477p.

HELLMERS, H.; BURTON, G.W. Photoperiod and temperature manipulation indices early anthesis in pearl illet. Crop Science, Madison, v.12, n.2, p.198-200, 1972.

HEPBURN, H.A.; POWELL, A.A.; MATHEWS, S. Problems associated with the routine application of electrical conductivity measurements of individual seeds in the germination testing of peas and soybeans. Seed Sicience and Technology, Zürich, v.12, n.2, p.403-413, 1984.

LEMOS, L.B.; NAKAGAWA, J.; CRUSCIOL, C.A.; CHINGNOLIJÚNIOR, W.; SILVA, T.R.B. Influência da época de semeadura e do manejo da parte aérea de milheto sobre a soja em sucessão em plantio direto. Bragantia, Campinas, v.62, n.3, p.405-415, 2003.

NETTO, D.A.; ANDRADE, R.V.; OLIVEIRA, A.C.; AZEVEDO, J.T.; BORBA,C.S.; ANDREOLI, C. Qualidade de sementes de milheto. (Pennisetum glaucum (L.) R. Br.) de diferentes procedências. Informativo ABRATES, Curitiba, v. 7, n. 3, p.48-53, 1997.

OLIVEIRA, J.B.; CAMARGO, M.N; ROSSI, M.; CALDERON FILHO, B. Mapa pedológico do Estado de São Paulo: legenda expandida. Campinas: Instituto Agronomico; Rio de Janeiro, EMBRAPA-Solos, 1999. 64p.: mapa.

PEREIRA, F.A.R. Cultivo de espécies visando a obtenção de cobertura vegetal do solo na entresafra da soja (Glycine max) (L.) Merril) no cerrado. 1990. 83f. Dissertação (Mestrado em Agronomia-Área de concentração agricultura) - Faculdade de Ciências Agronômicas, Universidade Estadual Paulista, Botucatu, 1990.

SALTON, J.C.; KICHEL, A.N. Milheto - Alternativa para cobertura do solo e alimentação animal. Dourados: EMBRAPA. 1997. Folheto.

SALTON, J.C. Opções de safrinha para agregação de renda nos cerrados. In: PLANTIO DIRETO NA INTEGRAÇÃO LAVOURA PECUÁRIA. Uberlândia: APDC, 2001. p.189-200.

SIDDIQUE, M.A.; GOODWIN, P.B. Conductivity measurements on single seeds to predict the germinability of French beans. Seed Science and Technology, Zürich, v.13, n.3, p.643-652, 1985.

SILVA, R.H. Crescimento radicular e nutrição de soja (Glycine max) em função da cultura anterior e da compactação em Latossolo Vermelho-escuro. 1998. 81 f. Dissertação (Mestrado em Agronomia - Área de Concentração Agricultura) - Faculdade de Ciências Agronômicas, Universidade Estadual Paulista, Botucatu, 1998.

TAO, J.K. Factors causing variations in the condutivity test for soybean seeds. Journal of Seed Technology, Lausing, v.3, n.1, p.10-18, 1978.

VIEIRA, R.D.; CARVALHO, N.M. Testes de vigor em sementes. Jaboticabal: FUNEP, 1994. 164p. 